\title{
Comparison of the effect of resin infiltrant, fluoride varnish, and nano-hydroxy apatite paste on surface hardness and streptococcus mutans adhesion to artificial enamel lesions
}

\author{
Mahdiye Aziznezhad ${ }^{1}$, Homayoon Alaghemand ${ }^{2}$,Zahra Shahande ${ }^{3}$, Nilgoon Pasdar ${ }^{4}$, Ali Bijani ${ }^{5}$, Abdolreza \\ Eslami $^{6}$, Zohre Dastan $^{7}$
}

\footnotetext{
${ }^{1}$ Postgraduate Student, Dental Materials Research Center, Department of Pediatric Dentistry, Babol University of Medical Sciences, Babol, Iran

${ }^{2}$ Associate Professor, Dental Materials Research Center, Department of Restorative Dentistry, Babol University of Medical Sciences, Babol, Iran

${ }^{3}$ Academic Member of Laboratorial Sciences Department, Babol University of Medical Sciences, Babol, Iran

${ }^{4}$ Assistant Professor, Dental Materials Research Center, Department of Pedodontics, Babol University of Medical Sciences, Babol, Iran

${ }^{5}$ Social determinants of Health Research Center, Health Research Institute, Babol University of Medical Sciences, Babol, Iran

${ }^{6} \mathrm{MD}$, Specialist of Infectious Disease, Infectious Diseases Research Center, Babol University of Medical Sciences, Babol, Iran

${ }^{7}$ MSc, Biochemistry Department, Babol University of Medical Sciences, Babol, Iran
}

\section{Type of article: Original}

\begin{abstract}
Introduction: Dental caries is a major public health problem, and Streptococcus mutans is considered the main causal agent of dental caries. This study aimed to compare the effect of three re-mineralizing materials: resin infiltrant, fluoride varnish, and nano-hydroxy apatite paste on the surface hardness and adhesion of Streptococcus mutans as noninvasive treatments for initial enamel lesions.

Methods: This experimental study was conducted from December 2015 through March 2016 in Babol, Iran. Artificial enamel lesions were created on 60 enamel surfaces, which were divided into two groups: Group A and Group B (30 subjects per group). Group A was divided into three subgroups (10 samples in each subgroup), including fluoride varnish group, nano-hydroxy apatite paste group (Nano P paste), and resin infiltrant group (Icon-resin). In Group A, the surface hardness of each sample was measured in three stages: First, on an intact enamel (baseline); second, after creating artificial enamel lesions; third, after application of re-mineralizing materials. In Group B, the samples were divided into five subgroups, including intact enamel, demineralized enamel, demineralized enamel treated with fluoride varnish, Nano P paste, and Icon-resin. In Group B, standard Streptococcus mutans bacteria adhesion (PTCC 1683) was examined and reported in terms of colony forming units (CFU/ml). Then, data were analyzed using ANOVA, Kruskal-Wallis, Mann-Whitney, and post hoc tests.

Results: In Group A, after treatment with re-mineralizing materials, the Icon-resin group had the highest surface hardness among the studied groups, then the Nano P paste group and fluoride varnish group, respectively $(\mathrm{p}=$ 0.035). In Group B, in terms of bacterial adhesion, fluoride varnish group had zero bacterial adhesion level, and then the Nano P paste group, Icon-resin group, intact enamel group, and the de-mineralized enamel group showed bacterial adhesion increasing in order $(\mathrm{p}<0.001)$.

Conclusion: According to the study among the examined materials, the resin infiltrant increased the tooth surface hardness as the intact enamel and fluoride varnish had the highest reduction level for bacterial adhesion. Nano P paste had an effect between the two materials, both in increasing surface hardness and reducing bacterial adhesion.
\end{abstract}

Keywords: Bacterial adhesion, Nano P paste, Surface hardness, Resin infiltrant, Fluoride varnish, Streptococcus mutans

\section{Corresponding author:}

Assistant Professor Dr. Nilgoon Pasdar, Babol University of Medical sciences, Babol, Iran.

Email: pasdar.nilgoon@gmail.com

Received: May 13, 2016, Accepted: July 01, 2016, Published: March 2017

iThenticate screening: July 02, 2016, English editing: October 19, 2016, Quality control: December 26, 2016

(C) 2017 The Authors. This is an open access article under the terms of the Creative Commons Attribution-NonCommercialNoDerivs License, which permits use and distribution in any medium, provided the original work is properly cited, the use is non-commercial and no modifications or adaptations are made. 


\section{Introduction}

In recent years, tooth decay control methods have changed dramatically. Traditional approaches with extensive restorations have changed to prevention, noninvasive, and minimal invasive methods. New procedures of controlling tooth decay, including preventive methods, risk control, and early diagnosis of caries, can help to stop this early enamel lesions at the early stages (1). White spot lesions (WSL) are identified with the loss of minerals, despite the hard dental surfaces. Risk factors are associated with poor oral hygiene and hypofunction of salivary glands. Early white spot lesions have hard surface and are reversible. Hypomineralization in the molar and incisor (MIH) is one of the other tooth enamel defects, which generally involves the anterior teeth and first permanent molars. This term was proposed in 2001 by Weerheijm et al. (2). Soft hypomineralized enamel is porous and prone to fractures because of its cavities and anomalies in the structure. Electron microscopy scans show that the enamel crystals in MIH are not organized, and there are few calcium and phosphate ions. Determining the etiologic factors is difficult due to the sensitivity of ameloblasts during the prenatal period to 3 years old, which is the mineralization period of the first permanent molars (3). However, most reported factors in the literature were related to changes in environmental conditions such as respiratory diseases, high fever, and multiple use of antibiotics. Treatment of teeth with MIH is varied as a simple process such as clinical dental control to different extensive restorative treatments. These patients can be treated by noninvasive and micro-invasive treatments in the early stages (2). Various methods have been proposed to treat these lesions. For the noninvasive treatment of these lesions, the oral hygiene instructions, nutritional advice and fluoride application, and using calcium and phosphate combinations, such as casein phosphopeptide-amorphous calcium phosphate (CPP-ACP) and xylitol (in the forms of candy, troche, syrup, and toothpastes containing xylitol) and antimicrobials (such as chlorhexidine varnish $1 \%$ with thymol $1 \%$ and chlorhexidine $0.12 \%$ ), and the surface seal of lesions are recommended $(4,5)$. However, many of these lesions progress due to the failure of patients to comply with the instructions. The next step is micro-invasive treatments, which include the use of capillary forces to drive resins with a high penetration index into the body of lesions and enamel cavities. This method was introduced in 2009 as the resin infiltration $(6,7)$. The third step is invasive treatments, including restorative treatments, which demolishes a large amount of healthy enamel tissue and which eventually enters the tooth in a vicious cycle of inevitable restorative treatments (7).

One of the noninvasive treatments is the re-mineralization with fluoride varnish. It is well confirmed that fluoride varnish is effective in preventing tooth decay. Fluoride varnish can improve and enhance the results of topical fluoride therapies by increasing the duration of exposure to the enamel. Due to its safety and effectiveness, its use has been increasing in recent years. Many studies suggest that anti-decay activity of fluoride varnish is related to its fluoride release and promoting the remineralization of enamel and preventing the enamel demineralization process. Less attention has been paid to the study of anti-biofilm activity of varnish, although one study has shown that fluoride can effectively affect bacterial adhesion to the tooth surface (8) and also can increase the surface hardness of enamel (9). Nano P Paste (FGM dental product, Brazil) is one of the calcium phosphate compounds that contains bioactive substances, including calcium and nanophosphate in the crystalline form of hydroxyapatite and fluoride with the concentration of $9000 \mathrm{ppm}$. Phosphate nanocrystals are smaller than $100 \mathrm{~nm}$, which can increase bioactivity and lead to an increase in surface area and the ability of moisture absorption in hydroxyapatite nanoparticles. The released calcium, phosphate, and fluoride ions can increase the saturation level in the liquid medium surrounding dental hard tissue and therefore promote remineralization (10). Less attention has been paid to the study of anti-biofilm activity of Nano P. Another method is the resin infiltration, which is a micro-invasive method for the treatment of hypomineralized enamel. In this method, after the surface erosion by acids, resin with low viscosity penetrates into the lesion with capillary forces, so the porosities of carious lesion are closed and the loss of minerals is stopped (11). This material penetrates into the body of the lesion without leaving a resin layer on the surface of the lesion and can seal it (12). Resin infiltrant have benefits, including mechanical resistance against enamel de-mineralization, preserving healthy tooth structure, and high patient acceptance. Another instance of its application is the covering of white spot lesions (WSL) after orthodontic treatments, in which, because of the similarity in the reflection coefficient of enamel and resin infiltrant, a white appearance of the lesion is resolved after resin infiltrant treatment, and the lesion color changes much like surrounding healthy enamel, without the need to remove some of the hard dental tissue, as in restorative and micro- abrasion methods (11). It has been claimed that it not only increases the surface hardness $(9,12)$ but also decreases bacterial adhesion $(9)$. The adhesion of certain microorganisms to specific surfaces in the oral cavity and the formation of dental plaque on teeth and restorative materials are the early causes of oral diseases such as gingivitis and tooth decay. The quantity and quality of bacterial accumulations on a specific surface depends on certain features. For example, high surface roughness and high free surface energy increases the bacterial adhesion (9). One of the main pathogens of tooth decay is Streptococcus mutans. This bacteria can cause synthesis of extracellular polysaccharides from sucrose, which causes 
adhesion of bacteria to tooth surfaces and formation of cariogenic biofilms. So if the adhesion of Streptococcus mutans to tooth surfaces reduces, the potential for initiation of dental decay will decrease (8). No data about influence of Nano P paste on Streptococcus mutans adhesion are available, and no studies have been conducted in regards to a re-mineralizing effect comparison with fluoride varnish and resin infiltrant. Also, no adequate information is available to compare the effects of these materials on anti-Streptococcus mutans adhesion; this study aimed to compare the anti-bacterial adhesion effect of Nano P paste, fluoride varnish, and resin infiltrant and compare their effects on enamel hardness.

\section{Material and Methods}

\subsection{Research design and samples}

This experimental study was conducted from December 2015 through March 2016 in Babol, Iran. According to similar studies, 30 intact premolars extracted for the orthodontic purposes with the maximum of 3 months duration after extraction and without any structural problems were chosen as the test samples (8). The teeth were cleaned and polished by pumice and water. To assess enamel defects, a stereomicroscope (Olympus Bx41, Olympus Optical Co, Tokyo, Japan) was used. All the teeth were stored before use in chloramine T 1\%. Two samples of proximal surface from each tooth were prepared. The approximate size of the samples was $3 \times 2 \times 2 \mathrm{~mm}$, which were measured using a demo cutting device (Delta precision sectioning machine, Mashhad, Iran) by diamond disc separator and low-speed hand-piece and water cooling system. The samples were randomly divided into two main groups: Group A, to evaluate the hardness using Vickers device (Koopa, MH3, Iran), and Group B, to examine the microbial adhesion. In Group A, samples were mounted in epoxy resin so that the enamel surface was out of the resin and placed parallel to the horizon.

\subsection{Production of artificial enamel lesions (demineralization and remineralization cycles)}

Putting enamel samples in a de-mineralization solution, which contains Cacl2: $12 \mathrm{mM}$, resin KH2PO4: $10 \mathrm{mM}$, Lactic acid: $50 \mathrm{mM}$, Nacl: $100 \mathrm{mM}, \mathrm{pH}=4.5$ at $37^{\circ} \mathrm{C}$ for 6 hours and then in the re-mineralization solution (Cacl2: $1.5 \mathrm{mM}$, KH2PO4: $5 \mathrm{mM}$, Acetic acid: $100 \mathrm{mM}$, Nacl: $100 \mathrm{mM}, \mathrm{PH}=6.5$ ) in $37^{\circ} \mathrm{C}$ for 18 hours. This process was repeated for 14 days $(5,9)$.

\subsection{Group $A$}

Group A, consisting of 30 samples of enamel preparations with the approximate size of $3 \times 2 \times 2 \mathrm{~mm}$, were mounted in epoxy resin in such a way that the enamel surface was out of the resin and placed parallel to the horizon. Group A was divided randomly into three subgroups of 10 samples (Groups A1-A3).

2.3.1. Group A1

In 10 enamel samples, a hardness test was done three times by Vickers device with $500 \mathrm{~g}$ force for 15 seconds. First time: in 3 points, the hardness was measured, and its average was reported without any surface preparation. Second time: after completion of the full cycle of de-mineralization and re-mineralization, the hardness was measured in three points, and its average was reported. Third time: after using the fluorilaq 5\% varnish (Pascal Company, USA), located as a thin layer by a brush and completely dried, hardness was measured in 3 points and its average was reported (Figure 1).

\subsubsection{Group A2}

Ten enamel samples, three times, were under hardness test such as in the first group. The first and second times were like the first group, but the third time, after applying Nano P paste (FGM dental product, Brazil), which was used by micro-brush rubbing motions for 10 seconds, the paste was placed on the enamel for 5 minutes (according to the manufacturer's instructions) and then was washed with water. Hardness was measured in 3 points and its average was reported.

\subsubsection{Group $A 3$}

Ten enamel samples, three times, were under hardness test as in the first group. The first and second times were similar to the first group, but the third time after applying Icon-resin (Icon, DMG, Hamburg, Germany), hardness was measured in 3 points, and its average was reported. Icon Etch was applied for 2 minutes on the sample; then, for at least 30 seconds, the samples were washed and dried using oil- and water-free spray (Table 1). Then, Icon Dry was placed for 30 seconds on the surface; then, for at least 30 seconds, the samples were washed and dried using oiland water-free spray. Icon infiltrant was located on the etched areas for 3 minutes and was cured for 40 seconds with LED (light emitting diode) (Valo Ultradent, USA). For the second time, Icon infiltrant was used for 1 minute; after removing the extra parts with an explorer, it was cured again for 40 seconds. Then, the results were analyzed using the SPSS software v.22, Anova, Anova repeated measures tests, Tukey post hoc test, and LSD; $<0.05$ was considered significant. 


\subsection{Determining the adhesion of Streptococcus mutans to enamel samples}

Group B was divided into the five subgroups ( $\mathrm{n}=6$ in each subgroup) as follows: 1) Group B1: intact enamel; 2) Group B2: hypomineralized enamel; 3) Group B3: hypomineralized enamel affected by fluorilaq varnish; 4) Group B4: hypomineralized enamel affected by the nano-hydroxyapatite paste; and 5) Group B5: the hypomineralized enamel affected by Icon-resin. Then, all the surfaces of the samples except one enamel surface was covered by two layers of nail polish. For 12 hours, the samples of intact enamel and enamel hypomineralized groups were put in Formalin tablets (Merck, Germany) for sterilization (13). Then, in the next three groups, the preparation of the samples was performed in a sterile environment with adequate ventilation and torch. After preparing, the samples were kept in a container with Formalin tablets for sterilization for 12 hours. After sterilizing, the samples were washed with distilled water, and the sterile swabs of bacterial suspension equivalent to 0.5 McFarland of standard bacteria Streptococcus mutans PTCC 1683 was spread on the sheep blood agar medium (SBA); then, the desired samples were put on the agar surface. Plates were incubated for $48 \mathrm{~h}$ at $37^{\circ} \mathrm{C}$. The samples were taken from the medium and washed with $15 \mathrm{cc}$ normal sterile saline solution, and then the samples were put in $1 \mathrm{cc}$ sterile saline solution (8) and for 5 minutes in the vortex (Delta vx2, Mashhad, Iran) with $2800 \mathrm{rpm}$, to remove the bacteria from the tooth surface and be spread in normal saline (removing bacteria phase followed by adhesion) (14). Then, dilutions of 1.10, 1.100, and 1.1000 of the above suspension were prepared in normal sterile saline (10) and $0.1 \mathrm{cc}$ of each dilution (14) was spread on the surface of SBA. Incubation was performed in $37^{\circ} \mathrm{C}$ for $18-24 \mathrm{~h}$ and then the grown colony count was counted and the results were reported in terms of CFU / $\mathrm{mL}$ (8). Then, the results were analyzed by IBM $\odot$ SPSS $\odot$ Statistics version 22 (IBM@ Corp., Armonk, NY, USA) using ANOVA, Kruskal-Wallis and Mann-Whitney post hoc tests.

Table 1. Composition and the manufactures of the materials

\begin{tabular}{|l|l|l|}
\hline Materials & Composition & $\begin{array}{l}\text { Manufacture Batch } \\
\text { number }\end{array}$ \\
\hline Icon & $\begin{array}{l}\text { Icon-Etch: hydrochloric acid, pyrogenic silicic acid, and surface } \\
\text { active substance. Icon dry: 99\% ethanol. Icon-infiltrant: } \\
\text { TEGDEMA-based resin matrix, imitators }\end{array}$ & $\begin{array}{l}\text { DMG, Hamburg, } \\
\text { Germany, Batch No: } \\
710377\end{array}$ \\
\hline $\begin{array}{l}\text { De-sensibilize } \\
\text { Nano P }\end{array}$ & $\begin{array}{l}\text { Calcium nanophosphate organized in crystalline form of hydroxyl } \\
\text { apatite, potassium nitrate, water, surfactant, tensoative, Flavor, 9.000 } \\
\text { ppm F }\end{array}$ & $\begin{array}{l}\text { FGM, Santa Catriuna, } \\
\text { Brazil, Batch No: 250815 }\end{array}$ \\
\hline $\begin{array}{l}\text { Fluorilaq } \\
\text { varnish }\end{array}$ & Naf 5\%, 22600ppm F & $\begin{array}{l}\text { Pascal, USA, Batch No: } \\
\text { BBVBZ }\end{array}$ \\
\hline
\end{tabular}

\section{Results}

Table 2 shows the Vickers hardness number (VHN) in intact enamel, after enamel lesion, and after treatment in all the groups. According to ANOVA analysis, there was no significant difference between the groups of the intact enamel (base line) $(\mathrm{p}=0.383)$. Post-lesion groups showed lower Vickers hardness number (VHN) compared with the base line. But no significant difference was observed in VHN between the groups after early enamel lesions $(\mathrm{p}=0.368)$. After using the mineralizing materials, the micro-hardness level was increased in all three groups, the resin infiltrant (Group A3) (453.13 \pm 102 ); next, the nanohyroxy apatite (Group A2) (66.406 \pm 57 ) and fluoride varnish (Group A1) (33.361 \pm 53 ), respectively. Significant differences were observed between the groups after treatment $(\mathrm{p}=0.035)$. Group A3 showed higher surface hardness than other groups, but the Tukey test results showed no significant difference between Groups A2 and A3. Also, there was no significant difference between the surface hardness of Groups A1 and A2. In addition, there was no significant difference between the resin infiltrant and intact enamel groups $(\mathrm{p}<0.001)$. But, in the other two groups, treated enamel had higher hardness than post-lesion enamel, but it was not as much as the intact enamel. Table 3 shows the adhesion level of Streptococcus mutans bacteria into five groups, according to CFU / mL. Kruskal-Wallis test results showed that in fluoride varnish group (Group B3), the adhesion level of this bacteria was zero, and then Nano P paste (Group B4) (78.33 \pm 52.69 ), resin infiltrant group (Group B5) (500 \pm 299.33$)$, the intact enamel (Group B1) (4651.6 \pm 3959.2$)$, and the hypomineralized enamel group (Group B2) (7883.3 \pm 7154.9 ), which had statistically significant differences in terms of bacterial adhesion $(\mathrm{p}<0.01)$. Figure 1 shows the surface hardness of the materials in three phases: baseline, post-lesion, and after applying the examined material 
http://www.ephysician.ir

Table 2. Mean surface microhardness values in baseline, post-lesion, and post-treatment groups, according to remineralizing agents applied

\begin{tabular}{|l|l|l|l|l|}
\hline Groups & $\begin{array}{l}\text { Baseline } \\
(\text { Mean } \pm \text { SD) }\end{array}$ & $\begin{array}{l}\text { Post-lesion } \\
(\text { Mean } \pm \text { SD) }\end{array}$ & $\begin{array}{l}\text { Post-treatment } \\
\text { (Mean } \pm \text { SD) }\end{array}$ & $\begin{array}{l}p \text {-value (ANOVA Repeated } \\
\text { measurement) }\end{array}$ \\
\hline $\begin{array}{l}\text { Fluoride varnish group } \\
\text { (Group A1) }\end{array}$ & $\begin{array}{l}454.73 \pm 72.80 \\
\text { a, A }\end{array}$ & $\begin{array}{l}303.03 \pm 47.45 \\
\text { b, A }\end{array}$ & $361.33 \pm 53^{\text {c, A }}$ & $p<0.001$ \\
\hline $\begin{array}{l}\text { Nano-hydroxy apatite } \\
\text { paste (Group A2) }\end{array}$ & $\begin{array}{l}482.63 \pm 81.99 \\
\text { a, A }\end{array}$ & $\begin{array}{l}323.23 \pm 64.58 \\
\text { b, A }\end{array}$ & $406.66 \pm 57^{\text {c, AB }}$ & $p<0.001$ \\
\hline $\begin{array}{l}\text { Resin infiltrant (group } \\
\text { A3) }\end{array}$ & $\begin{array}{l}433.93 \pm 77.62 \\
\text { a, A }\end{array}$ & $\begin{array}{l}286.26 \pm 58.9^{\text {b, }} \\
\text { A }\end{array}$ & $453.13 \pm 102^{\text {a, B }}$ & $p<0.001$ \\
\hline$p$-value (ANOVA) & 0.383 & 0.386 & 0.035 & \\
\hline
\end{tabular}

Table 3. Concentration of $S$. mutans on enamel surfaces (CFU/mL)

\begin{tabular}{|l|l|l|}
\hline Groups & Mean \pm SD & Min-max \\
\hline Sound enamel (Group B1) & $4651.66 \pm 3959.2^{\mathrm{a}}$ & $810-11500$ \\
\hline Hypomineralization enamel (Group B2) & $7154.9 \pm 753.33^{\mathrm{a}}$ & $3100-22000$ \\
\hline Fluoride varnish (Group B3) & $000^{\mathrm{b}}$ & 000.000 \\
\hline Nano hydroxyapatite paste (Group B4) & $78.33 \pm 52.69^{\mathrm{c}}$ & $20-150$ \\
\hline Resin infiltrant & $500 \pm 299.3^{\mathrm{d}}$ & $180-900$ \\
\hline$p$-value & $p<0.001$ & $p<0.001$ \\
\hline
\end{tabular}

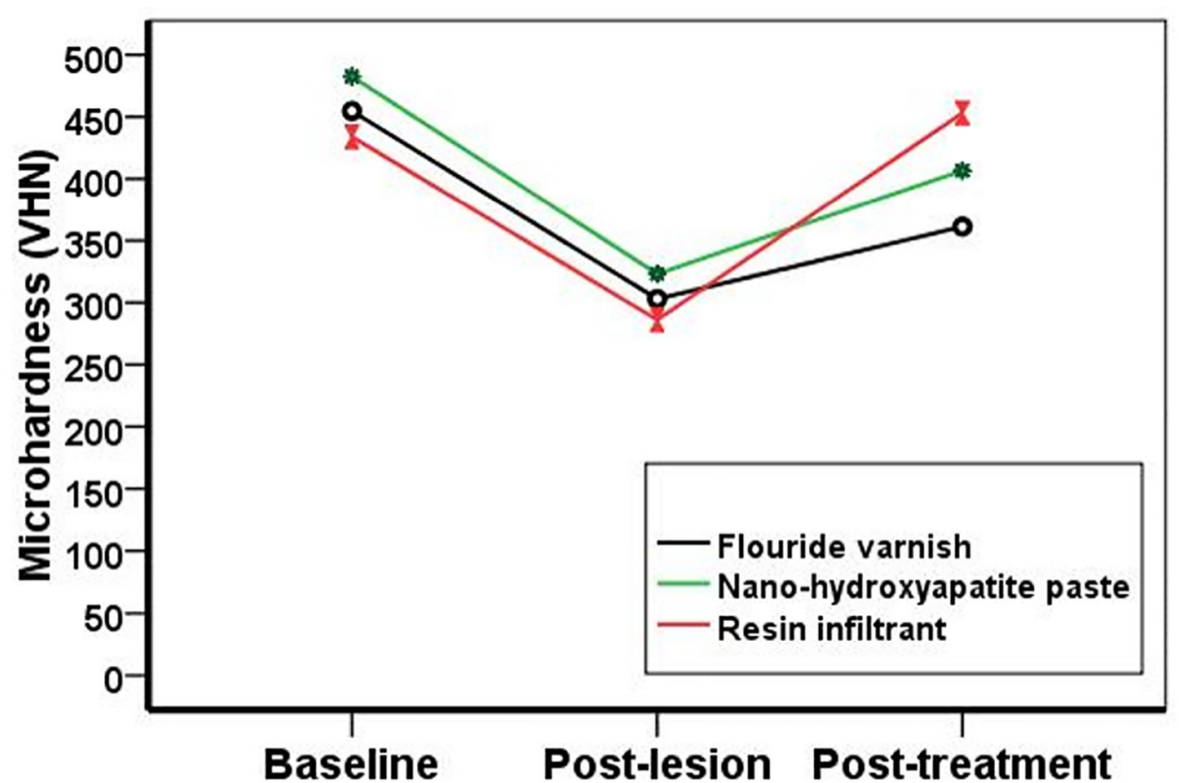

Figure 1. Surface hardness of the materials in three phases: baseline, post-lesion, and after applying the examined material

\section{Discussion}

Hardness means the resistance of a material or a surface against indentation or penetration, which is considered an important mechanical characteristics of the material because the resistance to abrasion, friction, erosion, or water or any other substance, in general, increases with increasing hardness. This means that high levels of mineral content in enamel are associated with low levels of abrasion compared with dentin. (9) Given the importance of surface enamel in progression of dental decay, one of the objectives of this study was to evaluate micro-hardness of an enamel surface, after creating the early enamel lesions and then using the mineralizing materials. Thus, measuring VHN (Vickers Hardness Number) was done in three steps: 1) on intact enamel (base line); 2) on the early enamel lesions such as white spot lesion; and 3) post-treatment (after applying the mineralizing materials) (10). After early decay lesions, decrease in VHN was observed in all groups. After treatment in all three groups, an increase in surface micro-hardness was seen in hypomineralized enamel. In this study, surface micro-hardness of enamel treated with resin infiltrant was significantly higher than in the other groups. This result can be due to the ability of low-viscosity 
resin to fill the lesion and create a barrier not only at the level of the lesion but also within the body of the enamel lesions. Thus, in theory, resin infiltrant is able to strengthen de-mineralized enamel structure and prevent more decay and pitting (9). Some clinical studies have reported that micro-invasive treatment of decay with resin infiltrant is an effective and safe method to stop early decay lesions and to preserve demineralized enamel $(15,16)$. A similar study conducted by Soley et al. evaluated the surface micro-hardness of de-mineralized enamel after resin infiltration and concluded that the resin infiltrant can increase the surface hardness of de-mineralized enamel, which is consistent with this study; its difference with our study was that we also examined the intact enamel as the control group and compared with the surface micro-hardness of treated enamel; we concluded that resin infiltrant can increase the surface micro-hardness of de-mineralized enamel as much as intact enamel. The findings of this study were consistent with the studies of Turres et al., Paris et al., Malek Taher et al., and Soley et al (9), which indicated that micro-hardness of decay lesions notably increased by the resin infiltrant $(1,4,7)$. After the resin infiltrant group, nano-hydroxyapatite group increased the surface microhardness of enamel slightly higher than fluoride varnish, but this difference was not statistically significant. According to company information, nano-hydroxyapatite paste contains $9000 \mathrm{ppm}$ fluoride. Although the Nano P paste contains a lower concentration of fluoride than varnish, the presence of organized calcium and phosphate ions in the form of nano-hydroxyapatite crystals with fluoride can increase the potential for remineralization. In white spot lesions, the hydroxyapatite crystals are dissolved from the superficial layer and create a lesion below the surface, with a high mineralized surface layer.

Nano-crystals of calcium and phosphate can have higher infiltration into the de-mineralized subsurface layers by rubbing motions for 10 seconds and may create a reservoir of calcium and phosphate ions. The source of ions with fluoride can be viable during the cariogenic challenge and help to maintain the supersaturated enamel minerals. However, the release of mineral ions into the deep areas of lesion can be avoided by this mineralized surface layer. This may explain why complete re-mineralization cannot be achieved following the nano-hydroxyapatite paste (10). The results of this study are consistent with the study of Carvalho et al. on increased surface hardness following the use of nano-hydroxyapatite paste. The authors examined the surface hardness of de-mineralized enamel after applying the nano-hydroxyapatite paste and fluoride varnish. They used de-mineralization and re-mineralization cycles for creating early enamel lesions and then measured the surface hardness of enamel after applying fluoride varnish and Nano P paste and concluded that both of them increase the surface hardness of enamel, but none of them can re-mineralize the enamel as much as the intact enamel and Nano P paste can increase surface hardness greater than fluoride varnish, which is consistent with our study. Although fluoride varnish has higher fluoride concentration (22600 ppm) compared with the Nano P paste (9000 ppm), it was suspected that the fluoride varnish group further increases the surface hardness due to higher concentrations of fluoride and the potential to reduce the dissolution of enamel in acid. The reason can be the low contact time of fluoride varnish with the enamel in our study because the fluoride varnish can have chemical reaction with enamel over 24 hours. On the other hand, more frequent application of fluoride varnish can enhance the effectiveness of anti-caries properties. But, in this study, one-time use of fluoride varnish was applied for the purpose of simulating professional clinical condition (10). The next group that increased the microhardness of hypomineralized enamel was the fluoride varnish group. Fluoride applies its anti-caries effect with three different mechanisms. First, it enters the fluoride ions in dental tissues and forms fluoro apatite by the present calcium and phosphate ions in saliva. This insoluble sediment replaces the dissolving salts containing manganese and carbonate, which were lost during de-mineralization by bacteria. This replacement process increases the enamel resistance to acid. Second, non-cavitated lesions are re-mineralized through a similar process; third, fluoride has antimicrobial activity. The results of this study on the increase in micro-hardness of de-mineralized enamel by fluoride varnish are consistent with the studies of Esfahani et al. (18), Lata et al. (19), Shetty et al. (20), Pulido et al. (15), and Vysal et al. (21). Streptococcus mutans is the most important pathogens in human dental decay. Its pathogenicity is due to its ability to bond to the tooth surface by formation of biofilm, which is created by organized polysaccharides derived from the metabolism of carbohydrates, especially sugar-containing diets. In addition to the metabolism of carbohydrates, bacterial products also can produce acidic materials that dissolve tooth enamel and cause tooth decay in the long term (16).

In the present study, the fluoride varnish group did not show any bacterial adhesion, and the number of $\mathrm{CFU} / \mathrm{mL}$ was zero. Fluoride has antimicrobial activity. At low concentrations, fluoride ions suppress glycosyltransferase enzyme production. Glycosyltransferase enables glucose consumption in the extracellular polysaccharides formation and increases bacterial adhesion. The formation of intracellular polysaccharides is prohibited by limiting microbial metabolism in hosts between meals, which prevents the accumulation of carbohydrates. As a result, the time of decay onset will be limited to the period during eating and immediately after that. At high concentrations (12.000 $\mathrm{ppm}$ ), which are used in the topical fluoride application, fluoride ions are toxic directly to some oral 
microorganisms, including Streptococcus mutans. Stopping the growth of mutans group of Streptococci after a single topical application of fluoride may continue for weeks (22). According to Dong et al., the minimum concentration (MIC) in which fluoride reduces bacterial adhesion is $282 \mathrm{ppm}$. In the study of Chen et al., fluoride varnish reduced adhesion of Streptococcus mutans. Chen prepared hydroxyl apatite discs, used four types of fluoride varnish, and measured the formation of cariogenic biofilm and adhesion of Streptococcus mutans on them at different times and concluded that fluoride varnish reduces the adhesion by $67 \%-98 \%$ (8), while in our study fluoride varnish reduced bacterial adhesion rate by $100 \%$. Also, in a study conducted by Soly et al., fluoride varnish was more effective in reducing bacterial adhesion compared with resin infiltrant, which is consistent with the results of this study (9). In vitro studies suggested that Streptococcus mutans and Lactobacillus acid productions decreased with a fluoride layer on the enamel. Also, the bacterial content increases by decreasing the fluoride concentration $(23,24)$. After the fluoride varnish group, the more effective group in reducing bacterial adhesion was nanohydroxyapatite paste. Nanosize hydroxyapatite has a protean hexagonal structure and adheres to oral streptococci, fills the microscopic defects on the enamel surface, and affects the oral microflora. Hydroxyapatite removes cariogenic bacteria from the oral cavity when it is used as an oral hygiene aid (14). Studies showed that oral bacteria are basically adhere to the rough surfaces of dental enamel cracks, and flat and smooth surfaces prevent bacterial adhesion. The results of this study are consistent with the Arakawal et al. study (14). Arakawal applied hydroxyl apatite paste with tray, cultivated the saliva samples, and concluded that the number of Streptococcus mutans colonies after applying hydroxyl apatite paste was 38\% lower than baseline. After the nano-hydroxyl paste group, the resin infiltrant group had reduced bacterial adhesion compared with the hypomineralized enamel and intact enamel groups because resin infiltrant filled the microporosities of demineralized enamel, decreased enamel surface roughness, and created a smooth surface because the rough surface increases bacterial adhesion and prepares a space for the evolution of cariogenic plaques $(9,25,26)$. These results are consistent with the study by Soley et al. Among the studied groups, the highest bacterial adhesion was related to hypomineralized enamel, which can be due to surface microporosities. Poggio and Eick evaluated the surface morphology of restorative materials and its association with the adhesion of Streptococcus mutans; the authors concluded that bacterial adhesion is not related to surface roughness of materials and depends on other factors such as the electrical characteristics of material, its hydrophobicity, surface energy, and the amount of fluoride release, among which the electrical characteristics and hydrophobicity are the most important factors in the early adhesion of bacteria (25). Their results were inconsistent with the present study. In agreement with our study, other authors such as Quirynen and Carlen stated that the rougher surfaces absorb more salivary proteins and, consequently, more bacteria (25). In the present study, the adhesion of Streptococcus mutans in hypomineralized enamel was more than the intact enamel, which can be due to the surface porosities after being in the de-mineralization and re-mineralization cycles, although the difference was not statistically significant (14). The period for de-mineralization in the $\mathrm{pH}$ cycling phase was based on early studies to simulate the duration of de-mineralization that can occur in the oral cavity. However, it is relevant to emphasize that numerous dissimilarities exist between cycling models and in vivo. Thus, the re-mineralizing agent tested in our study also should be evaluated in vivo.

\section{Conclusions}

The finding of our study demonstrated that, among the tested dental materials, resin infiltrant further increased dental surface hardness, and fluoride varnish further reduced bacterial adhesion; Nano P paste had an effect between the two materials, both in increasing surface hardness and reducing bacterial adhesion. It is recommended that further research should be conducted on the effectiveness of Nano P in reducing bacterial adhesion.

\section{Acknowledgments:}

This work was supported by grant number 9440727 provided by Babol University of Medical Sciences, Research and Technology Center, and Dental Material Research Center and Material Laboratory of Noshirvani Engineering University of Babol. We appreciate the technical assistance of Professor Poor Amir, Mrs. Seddighian, and Mrs. Dastan. We also are grateful to the FGM Company for preparation of the Nano P paste. We thank the reviewers of Electronic Physician Journal for their constructive comments that enhanced the quality of the paper.

\section{Conflict of Interest:}

There is no conflict of interest to be declared.

Authors' contributions:

All authors contributed to this project and article equally. All authors read and approved the final manuscript. 


\section{References:}

1) Doméjean S, Ducamp R, Léger S, Holmgren C. Resin infiltraon of non-cavitad caris lesions: a systematic review. Med Princ Pract. 2015; 24(3): 216-21. doi: 10.1159/000371709. PMID: 25661012.

2) Crombie FA, Cochrane NJ, Manto DJ, Palamara JE, Reynolds EC. Mineralisation of developmentary hypomineralised human enamel in-vitro. Caries Res .2013; 47(3): 259-63. doi: 10.1159/000346134. PMID: 23363890.

3) Masteroberardino S, Campus G, Strohmenger L,Villa A, Cagetti M. An Innovative approach to treat incisors hypomineralization (MIH): a combined use of casein phosphopeptide-amorphous calcium phosphate and hydrogen peroxide-a case report. Case Rep Dent. 2012; 379-593. doi: 10.1155/2012/379593.

4) Pickelt FA. Nonfluoride caries preventive agents: new guidelines. J Contemp Dent Pract. 2011; 126(6): 469-74.

5) Cochrane NJ, Cai F, Huq NL, Burrow MF, Reynolds EC. New approaches to Enhanced remineralization of tooth enamel. J Dent Res. 2010; 89(11): 1187-97. doi: 10.1177/0022034510376046. PMID: 20739698.

6) Taher NM, Alkhamis HA, Dowaidi SM. The influence of resin infiltration system enemal microhardness and surface roughness: An in vitro study. Saudi Dent J. 2012; 24(2): 79-84. doi: 10.1016/j.sdentj.2011.10.003. PMID: 23960533, PMCID: PMC3723288.

7) Paris S, Schwendicke F, Seddig S, Muller WD, Dorfer C, Meyer- lueckel H. Micro- hardness and mineral loss of enamel lesions after infiltration with various resins: influence of infiltrant composition and application frequency in-vitro. J Dent. 2013; 41(6): 543-8. doi: 10.1016/j.jdent.2013.03.006.

8) Chau NP, Pandit S, Jung JE, Jeon JG. Evaluation of streptococcus mutans adhesion to fluoride varnishes and subsequent change in biofilm accumulation and acidogenicity. J Dent. 2014; 42(6): 726-34. doi: 10.1016/j.jdent.2014.03.009. PMID: 24694978.

9) Soley A, Orcun Y, Atalay M, Suat OC, Sezer DB. Effect of resin infiltration on enamel surface properties and streptoccuse mutans adhesion to artificial enamel lesions. Dent Mater J. 2015; 34(1): 25-30. doi: 10.4012/dmj.2014-078. PMID: 25748455.

10) de Carvalho FG, Vieira BR, Santos RL, Carlo HL, Lopes PQ, de Lima BA. In vitro effects of nanohydroxyapatite paste on initial enamel carious lesions. Pediatr Dent. 2014; 36(3): 85-9. PMID: 24960376.

11) Torres CR, Rosa PC, Ferreir NS, Borges AB. Effect of caries infiltration technique and fluoride therapy on microhardness of enamel carios lesion. Oper Dent. 2012; 37(4): 363-9. doi: 10.2341/11-070-L. PMID: 22335304.

12) Paris $S$, Dörfer CE, Meyer-Lueckel H. Surface conditioning of natural enamel caries lesions in deciduous teeth in preparation for resin infiltration. J Dent. 2010; 38(1): 65-11. doi: 10.1016/j.jdent.2009.09.001. PMID: 19737595.

13) Tydell PA. Nosocomail infection control during construction and renovation of health care facilitis. Infection control today. 2002; 6(6): 47-9.

14) Arakawa $T$, Fujimaru $T$, Ishizak $T$, Takeuchi $H$, Kageyama $M$, Ikemi $T$, et al. Unique function of hydroxyapatite with mutans streptococci adherence. Qunitessence Int. 2010; 41(1): 11-9. PMID: 19907724.

15) Pulido MT, wefel JS, Hernandez MM, Denehy GE, Guzmen-Armstrong S. The inhibitory effect of MI paste, fluoride and a combination of both on the progression of antificial caries like lesions in enamel. Oper Dent. 2008; 33(5): 550-5. doi: 10.2341/07-136. PMID: 18833861.

16) Angius F, madeddu M, Pompei R. Nuttritionally variant Streptococei interfere with streptococcus mutans adhesion properties and biofilm formation. New Microbiol. 2015; 38(2): 259-66. PMID: 25938751.

17) Paris S, Schwendicke F, Seddig S, Muller WD, Dorfer C, Meyer H. Micro- hardness and mineral loss of enamel lesion after infiltration with various resins: Influence of infiltrent composition and application frequency in vitro. J Dent. 2013; 41(6): 543-8. doi: 10.1016/j.jdent.2013.03.006. PMID: 23571098.

18) Salehzadeh Esfahani K, Mazaheri R, Pishevar L. Effect of Treatment with various remineralizating agents on the microhardness of demineralized enamel surface. J Dent Res Dent Clin Dent Prospects. 2015; 9(4): 239-45. doi: 10.15171/joddd.2015.043. PMID: 26889361, PMCID: PMC4753033.

19) Lata S, Uerghese No, Varughese JM. Remineralization potential of flouride and amorphous calcium phosphate-Casein phospher peptide on enamel lesions: an in vitro comparative evaluation. J Conserv Dent. 2010; 13(1): 42-6. doi: 10.4103/0972-0707.62634. PMID: 20582219, PMCID: PMC2883807.

20) Shetty S, Hegde MN, Bopanna TP. Enamel remineralization assessment after treatment with three different remineralizing agents using surface microhardness: An in vitro study. J conseru Dent. 2014; 17(1): 49-52. doi: 10.4103/0972-0707.124136. PMID: 24554861, PMCID: PMC3915386. 
21) Vysal T, Amasyali M, koyuturk AE, Ozcen S. Effect of difference topical agent on enamel demineralizations around onthodentics brackets an in vivo and in vitro study. Aust Dent J. 2010; 55(3): 268-74. doi: 10.1111/j.1834-7819.2010.01233.x. PMID: 20887513.

22) Andre V, Scott E, Terence E. Dental caries: etiology, Clinical characteristics, Risk assessment, and management in: Art and science of operative dentistry. Canada, Elsevier. 2014; 76-9.

23) pinar Erdem A, Sepet E, kulekei G, Trosol SC, Guver Y. Effect of two fluoride Varnishes and one fluoride cholonhexidine varnish on streptoccus mutans and streptococcus sobrinus biofilms formation in vitro. Int $\mathrm{J}$ med sci. 2012; 9(2): 129-36. doi: 10.7150/ijms.3637. PMID: 22253559, PMCID: PMC3258554.

24) Van Laveren C. Antimicrobial activity of fluoride and its in vivo impontarce identification of research questions. Caries Res. 2001; 35(1): 65-70. doi: 10.1159/000049114. PMID: 11359062.

25) Poggio C, Arcioia C, Rosti F, Scribant A, Saino E, Visai L. Adhesion of Streptococcus mutans to different restorative materials. Int J organs. 2009; 32(9): 671-7.

26) Wany Ch, Zhao Y, Zhang S. Effect of enamel morphology on nanoscale adhesion forces of streptococcal bacteria: An AFM study. Scanning. 2015; 37(5): 313- 21. doi: 10.1002/sca.21218. PMID: 26482011. 